\title{
Rancang Bangun dan Analisa Ekonomi Mesin Pengiris Adonan Kerupuk Merah Tipe Piringan Pisau Vertikal
}

Hadijah putri Mahrani*, Hendra, Khairul Febri, Muhammad Irfan Maulana Sitorus, Abdi Fauzan, Rafki, Elvin Hasman, Fanny Yuliana Batubara, Jamaluddin

Program Studi Teknologi Mekanisasi Pertanian, Politeknik Pertanian Negeri Payakumbuh, Limapuluh Kota, Indonesia

*Penulis Korespondensi:

Email: putrihadijah77@gmail.com

\begin{abstract}
Abstrak. Kerupuk adalah makanan kering yang sangat populer di Indonesia, sehingga permintaan masyarakat terhadap kerupuk cukup tinggi. Alat pengiris adonan kerupuk secara mekanis mampu melakukan pengirisan kerupuk dalam jumlah banyak dengan ketebalan hasil irisan relatif sama dan dapat mengurangi resiko kecelakaan kerja. Metode pelaksanaan dalam pembuatan mesin pengiris adonan kerupuk merah ini dimulai dari perancangan alat secara fungsional dan struktural, pengujian kinerja alat dan analisa ekonomi teknik. Kapasitas alat pengiris adonan kerupuk yaitu 182,524 kg/jam, rata-rata persentase kerusakan hasil 38\% dan rata-rata ketebalan hasil irisan 2,12 mm. Hasil analisis ekonomi alat pengiris adonan kerupuk didapat biaya tetap Rp. 1.27.130/tahun, biaya tidak tetap Rp. 16.986/jam, biaya pokok Rp. $61,194 / \mathrm{kg}$, dan break event point Rp. $2.823,55 \mathrm{~kg} / \mathrm{thn}$.
\end{abstract}

Kata Kunci: kerupuk merah,mesin pengirisan, pisau piringan vertical, analisa ekonomi

\section{Pendahuluan}

Pengirisan adonan merupakan salah satu tahapan dalam produksi kerupuk merah yang memerlukan ketelitian tinggi. Pengirisan akan mempengaruhi proses pengeringan dan penggorengan kerupuk. Adonan kerupuk merah yang terlalu tebal akan memperlama waktu pengeringan sedangkan jika adonan terlalu tipis akan menyebabkan kerupuk mudah patah (Ratnawati, 2013).

Pengirisan adonan kerupuk merah dapat dilakukan secara manual dan mekanis. Pengirisan secara manual memiliki kekurangan dimana tingkat produktivitas rendah dan resiko kecelakaan kerja besar. Pengirisan adonan kerupuk menggunakan mesin dapat mempermudah dan mempercepat proses pengirisan dalam produksi kerupuk merah. Selain itu, pengirisan menggunakan mesin diharapkan mampu mengurangi resiko kecelakaan kerja.

Berdasarkan alasan di atas, pembuatan mesin pengiris adonan kerupuk merah tipe piringan pisau vertikal diharapkan dapat mempermudah proses pengirisan adonan kerupuk dengan resiko kecelakaan kerja yang lebih rendah.

\section{Bahan dan Metode}

\section{Alat dan Bahan}

Alat yang digunakan dalam pelaksanaan kegiatan pembuatan mesin pengiris adonan kerupuk merah yaitu mesin las listrik, mesin bor, mesin bubut, mesin gerinda tangan, mesin 
gerinda potong, rol siku, meteran, kunci - kunci, motor listrik, mesin pemotong, gerinda duduk dan palu.

Bahan - bahan yang digunakan dalam pembuatan mesin pengiris adonan kerupuk merah yaitu plat stainless, baut, mur, elektroda, bantalan ucp, pisau, puli, besi siku, belt, mata gerinda potong, paku rivet, mata bor, besi poros, motor listrik.

Metode kegiatan penelitian yang digunakan yaitu metode rancangan fungsional dan struktural dari komponen. Kegiatan yang dilakukan dalam penelitian ini terdiri dari dua tahap yaitu tahap pertama berupa penelitian pendahuluan berupa studi literatur dan perancangan alat dan tahap kedua yaitu kegiatan pembuatan komponen, perakitan, uji kinerja dan analisis.

\section{Hasil dan Pembahasan}

\section{Rancangan Mesin}

Pada prinsipnya mesin ini menggunakan tenaga putaran untuk mengiris bahan yang dimasukkan ke dalam hopper oleh pisau pengiris yang berputar dengan kecepatan rendah. Rancangan fungsional dan struktural dari mesin ini adalah memberikan gambaran mengenai dimensi, posisi dan fungsi dari masing-masing komponen mesin ini. Rancangan keseluruhan mesin pengiris adonan kerupuk merah tipe piringan pisau vertikal dapat dilihat pada Gambar 1.

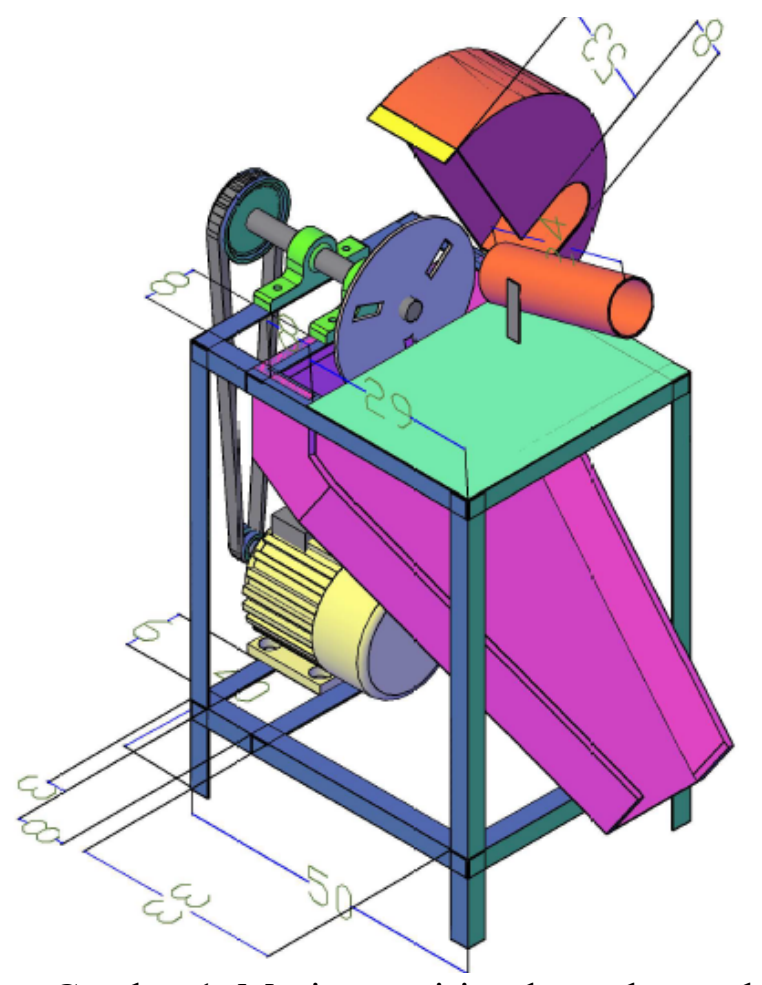

Gambar 1. Mesin pengiris adonan kerupuk

Rangka

Rangka utama berfungsi sebagai penopang atau penyangga seluruh komponen pada mesin. Terbuat dari besi siku dengan ukuran panjang $50 \mathrm{~cm}$, lebar $40 \mathrm{~cm}$ dan tinggi $70 \mathrm{~cm}$. Rangka dapat dilihat pada Gambar 2. 


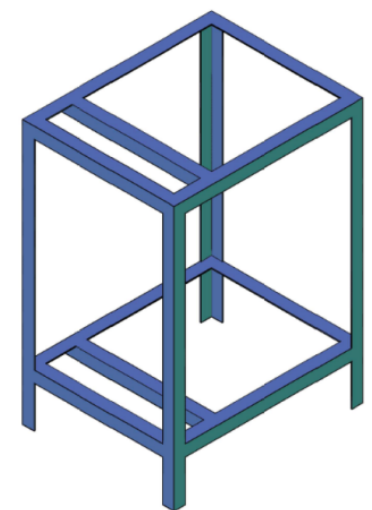

Gambar 2. Rangka

Motor listrik

Motor listrik berfungsi sebagai penggerak pada mesin pengiris adonan kerupuk. Motor listrik yang digunakan bertenaga $1 / 2 \mathrm{Hp}$ dengan $1430 \mathrm{Rpm}$. Motor listrik dapat dilihat pada Gambar 3.

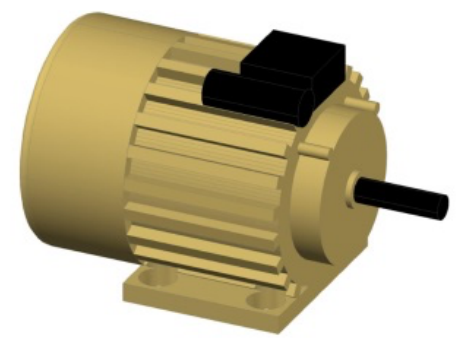

Gambar 3. Motor listrik

\section{Hopper}

Hopper berfungsi sebagai tempat pemasukan adonan kerupuk yang akan diiris oleh pisau pengiris. Hopper berdiameter $8 \mathrm{~cm}$ dengan panjang $24 \mathrm{~cm}$ dengan kemiringan $28^{\circ}$. Hopper dapat dilihat pada Gambar 4.

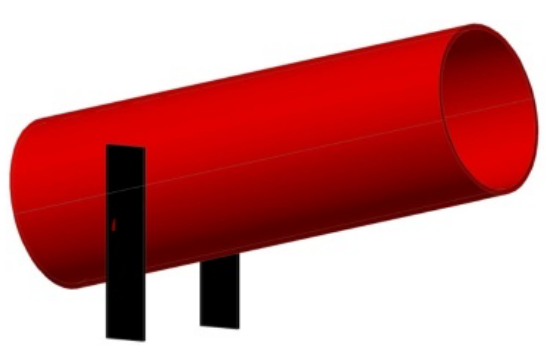

Gambar 9. Hopper

Piringan pisau

Pisau berfungsi sebagai pengiris kerupuk berbentuk lontongan pada mesin pengiris adonan kerupuk tipe pisau horizontal. Pisau berdiameter $30 \mathrm{~cm}$ dengan ketebalan $1 \mathrm{~cm}$ memiliki 3 mata pisau. Pisau dapat dilihat pada Gambar 5. 


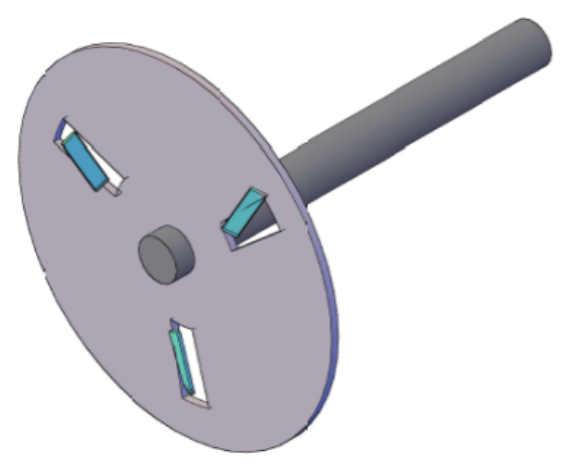

Gambar 5. Pisau

\section{Outlet}

Outlet berfungsi sebagai saluran pengeluaran kerupuk setelah diiris. Outlet terbuat dari plat stainless berukuran $1 \mathrm{~mm}$, panjang $65 \mathrm{~cm}$ dan lebar $38 \mathrm{~cm}$, dengan kemiringan $60^{\circ}$. Outlet dapat dilihat pada Gambar 6.

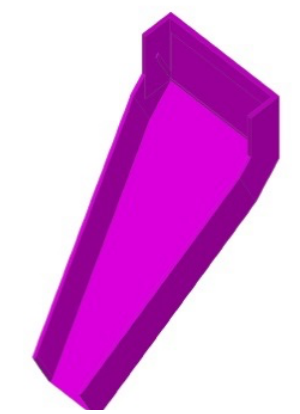

Gambar 6. Outlet

Penutup pisau

Penutup pisau berfungsi untuk menutup piringn pisau agar saat mesin beroperasi kecelakaan kerja seperti tangan teriris dapat dicegah. Penutup pisau dengan panjang $35 \mathrm{~cm}$, tinggi $18 \mathrm{~cm}$ dan lebar $14 \mathrm{~cm}$ penutup pisau dapat dilihat pada Gambar 7.

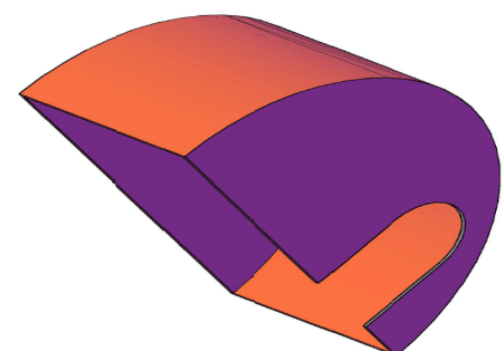

Gambar 7. Penutup pisau

Hasil perakitan mesin pengiris adonan kerupuk merah tipe piringan pisau vertikal dapat dilihat pada Gambar 8. 


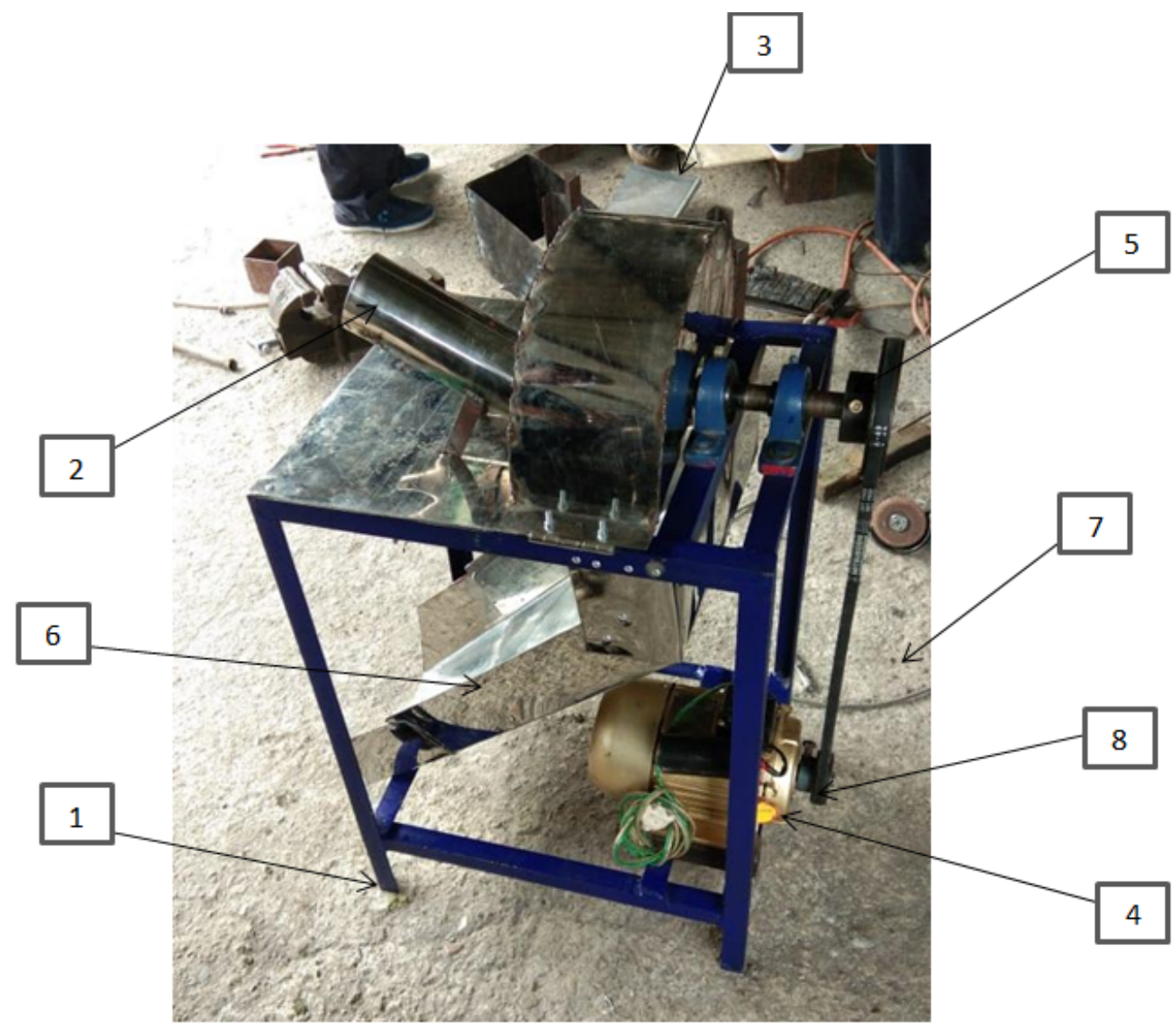

Gambar 8. Mesin pengiris adonan kerupuk

Keterangan Gambar 8:

1. Rangka

2. Hopper

3. Penutup pisau

4. Daya penggerak
5. Bantalan ucp

6. Outlet

7. Belt

8. Puli

\section{Uji Kinerja Mesin}

Perhitungan yang diperlukan sebelum uji kinerja mesin yaitu:

Kadar air adonan

Pengujian kadar air adonan bertujuan untuk mengetahui berapa kandungan kadar air yang baik pada adonan kerupuk yang akan diiris. Menurut Winarno (1993), kadar air suatu bahan biasanya dinyatakan dalam persentase kadar air basis basah(bb) dan kadar air basis kering (bk). Kadar air berat basah (wet basis) adalah perbandingan antara berat air didalam bahan dengan berat bahan basah. Dari pengujian kadar air berat basah adonan kerupuk yang dilakukan di Laboratorium Politeknik Pertanian Negeri Payakumbuh, didapat hasil kadar air pada adonan kerupuk sebagai berikut:

$\mathrm{Kab}=\frac{\mathrm{Wa}-\mathrm{Wb}}{\mathrm{Wa}} \times 100 \%=\frac{(10,3559+3,1786)-9,166}{10,3559} \times 100 \%=37,88 \%$

Dimana : 
$\mathrm{Kab}:$ Kadar air basis basah

Wa : Berat awal (\%bb)

$\mathrm{Wb}$ : Berat kering/konstan $(\mathrm{Kg})$

Adonan yang telah siap diiris dapat dilihat pada Gambar 9.

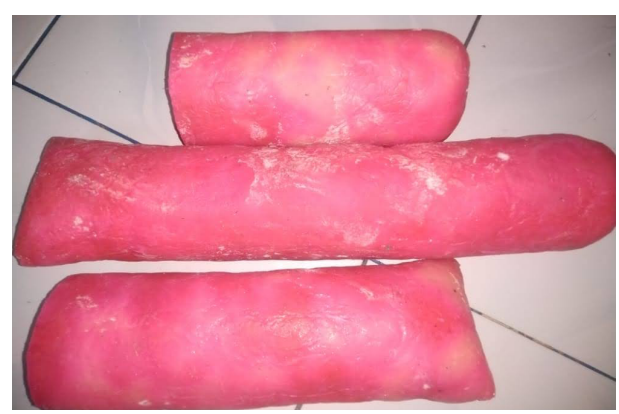

Gambar 9. Bahan adonan kerupuk

Hasil irisan yang bagus dapat dilihat pada Gambar 10.

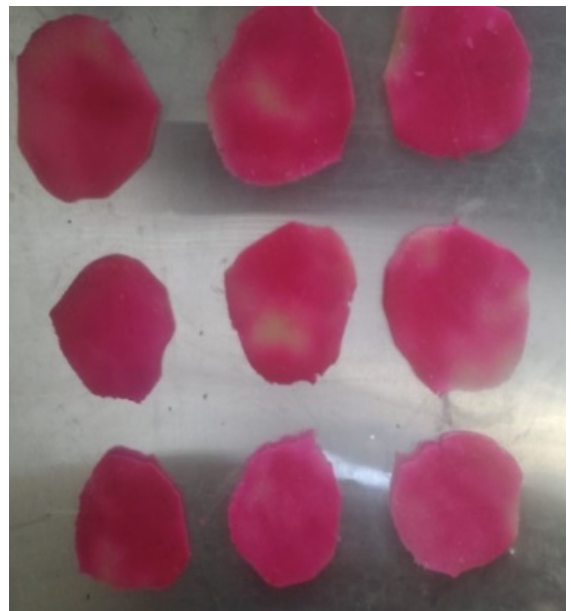

Gambar 10. Hasil irisan bagus

Hasil irisan yang rusak dapat dilihat pada Gambar 11 .

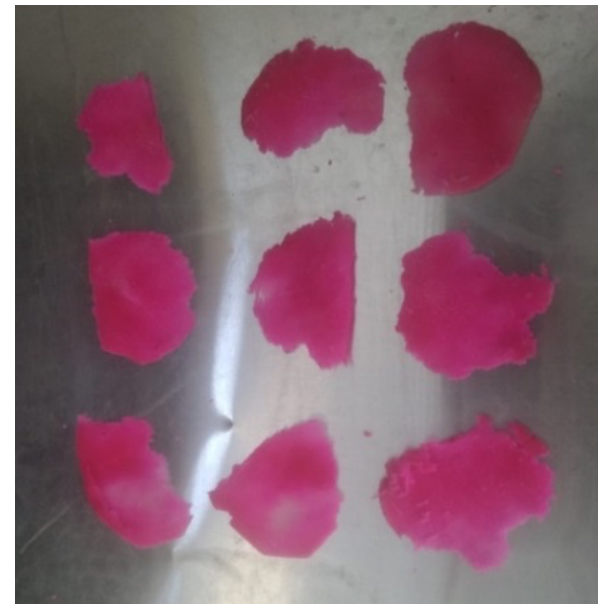

Gambar 11. Hasil irisan rusak

Pengujian kinerja mesin pengiris adonan kerupuk merah tipe piringan pisau vertikal dapat dilihat pada Tabel 1 . 
Kapasitas mesin

Kapasitas mesin merupakan kemampuan mesin mengiris lontongan kerupuk dalam satu jam (Irwan \& Novita, 2016). Rumus menghitung kapasitas seperti pada Persamaan 2 (Nasution et al., 2018; Baskara, et al., 2018):

$\mathrm{C}=\frac{\text { berat hasil }(\mathrm{kg})}{\text { waktu kerja }(\mathrm{Jam})}=\frac{1,6(\mathrm{~kg})}{0,00549(\mathrm{Jam})}=291,438 \mathrm{~kg} / \mathrm{jam}$

Keterangan:

$\mathrm{C}=$ Kapasitas alat $(\mathrm{kg} / \mathrm{Jam})$

Tabel 1. Hasil uji kinerja

\begin{tabular}{lcccc}
\hline \multirow{2}{*}{ Parameter Hasil Pengujian } & Pengujian & Pengujian & Pengujian & \multirow{2}{*}{ Rata-rata } \\
\hline Berat bahan baku awal (kg) & 1 & 2 & 3 & \\
Berat bahan teriris bagus (kg) & 1,6 & 1,6 & 1,6 & 1,6 \\
Berat bahan teriris rusak(kg) & 0,95 & 0,92 & 1,1 & 0,99 \\
Ketebalan rata-rata hasil irisan (mm) & 0,65 & 0,68 & 0,5 & 0,61 \\
Waktu (jam) & 2,08 & 2,28 & 2,02 & 2,12 \\
Rpm dengan beban & 0,00518 & 0,00578 & 0,00541 & 0,00549 \\
Rpm tanpa beban & 371,78 & 369,6 & 370 & 370,46 \\
Kapasitas mesin pengiris (kg/jam) & 376 & 376 & 376 & 376 \\
\hline
\end{tabular}

Rpm

Rpm (rotation per minute) merupakan jumlah putaran dalam satu menit. Dalam pembuatan mesin ini perlu menghitung Rpm nya sehingga nanti diperoleh Rpm yang tepat dalam proses pengirisan adonan. Jika Rpm terlalu rendah maka pengirisan kurang efesien dan jika Rpm terlalu tinggi akan mengakibatkan hasil dari irisan rusak atau hancur. Rumus menghitung Rpm yaitu, jumlah putaran awal dibagi ratio gear ataupun puli.

Loses (kerusakan hasil)

Persentase rusak $=\frac{\text { Berat adonan rusak }(\mathrm{kg})}{\text { Berat awal }(\mathrm{kg})} \times 100 \%=\frac{0,61 \mathrm{~kg}}{1,6 \mathrm{~kg}} \times 100 \%=38 \%$

\section{Analisis Ekonomi Alat}

Asumsi:

Harga jual (P)

$=$ Rp. 3.803 .800

Umur ekonomis alat (n)

$=4$ tahun

Harga akhir (S)

$=10 \% * \mathrm{P}$

Bunga modal (I)

$=12 \% /$ tahun

Jam kerja/tahun (x)

$=1.470 \mathrm{jam} / \mathrm{tahun}$

Jam kerja /hari

$=5 \mathrm{jam}$

Upah operator (Rp)/hari

$=$ Rp. 80.000 
Jumlah operator

Kapasitas

Upah operator

Biaya tetap

Biaya tetap adalah biaya minimal yang harus dikeluarkan oleh suatu perusahaan atau organisasi walaupun alat dan mesin tidak dioperasikan. Komponen biaya tetap untuk mesin pengiris adonan kerupuk terdiri dari penyusutan dan bunga modal.

Biaya penyusutan (D)

Biaya penyusutan adalah pemerosotan harga suatu barang atau alat dikarenakan seiring berjalannya waktu akibat pertambahan umurnya (Irwan \& Novita, 2016). Perhitungan biaya penyusutan dapat dilihat seperti dibawah ini (Azima et al., 2018; Jabbar et al., 2018):

$\mathrm{S}=10 \% \times \mathrm{P}=10 \% \times \mathrm{Rp} 3.803 .800=\mathrm{Rp} .380 .380$

D $\quad$ Rp $3.803 .800-R p 380.380$

Keterangan :

$$
4 \quad=\text { Rp } 855.855 \text { /tahun }
$$

$\mathrm{D}=$ Biaya penyusutan $(\mathrm{Rp} / \mathrm{Thn})$

$\mathrm{P}=$ Harga jual (Rp)

$\mathrm{S}=$ Harga akhir (Rp) $/ 10 \% \times \mathrm{P}$

$\mathrm{N}=$ Perkiraan umur ekonomis (tahun)

Bunga modal (I)

Bunga modal adalah sejumlah uang yang dibayarkan atas penggunaan uang yang dipinjam (Putera et al., 2019).

$\mathrm{I}=\frac{i(P)(n+1)}{2 n}=\frac{12 \%(\mathrm{Rp} \mathrm{3.803.800)(4+1)}}{2 \times 4 \text { tahun }}=\mathrm{Rp} 285.285 /$ tahun

Keterangan :

$\mathrm{I}=$ bunga modal $(\mathrm{Rp} / \mathrm{thn})$

$\mathrm{i}=$ suku bunga bank $(\% / \mathrm{Thn})$

Total biaya tetap $(\mathrm{BT})=$ biaya penyusutan + bunga modal

$$
=\text { Rp. } 855.8555 / \text { tahun }+ \text { Rp. } 285.285 / \text { tahun }=\text { Rp. 1.141.140/tahun }
$$

\section{Biaya tidak tetap}

Pada biaya tidak tetap, jumlah yang akan dikeluarkan per unit atau per aktivitas justru berjumlah tetap sedangkan untuk biaya secara total jumlahnya akan menyesuaikan dengan banyaknya jumlah unit yang diproduksi ataupun jumlah aktivitas yang dilakukan. Biaya tidak tetap juga merupakan biaya yang dikeluarkan jika alat dan mesin dioperasikan. Biaya tidak 
tetap didapat dari jumlah upah operator, biaya pemeliharaan dan biaya listrik adalah sebesar Rp 16.949 /jam. Perhitungan biaya tidak tetap secara lengkap adalah sebagai berikut (Jabbar et al., 2018):

Upah operator $/ \mathrm{jam}=\frac{\text { Upah }(\mathrm{Rp}) / \text { hari } \mathrm{x} \text { jumlah operator }}{\text { Jam kerja } / \text { hari }}=\frac{\mathrm{Rp} 80.000 \times 1}{5 \text { jam } / \text { hari }}=\mathrm{Rp} .16 .000 / \mathrm{jam}$

Biaya pemeliharaan $=\frac{1,2 \%(\mathrm{P}-\mathrm{S})}{100 \mathrm{jam}}=\frac{1,2 \% x(R p 3.803 .800-R p 380.380)}{100 \mathrm{jam}}=\mathrm{Rp} \mathrm{410,810/ \textrm {jam }}$

Biaya listrik PLN = Daya $\times$ Harga listrik $/ \mathrm{kwh}=0,37285 \mathrm{kw} \times \mathrm{Rp} .1 .444 / \mathrm{kwh}$

$$
=\operatorname{Rp} 538,3954 / \mathrm{jam}
$$

Total biaya tidak tetap $($ BTT $)=$ upah operator + biaya pemeliharaan + biaya listrik

$$
\begin{aligned}
& =\operatorname{Rp} .16 .000 / \mathrm{jam}+\mathrm{Rp} .410,810 / \mathrm{jam}+\mathrm{Rp} 538,3954 / \mathrm{jam} \\
& =\operatorname{Rp} 16.949 / \mathrm{jam}
\end{aligned}
$$

Biaya pokok (BP)

Biaya pokok adalah biaya yang diperlukan oleh suatu mesin untuk setiap unit produksi. Rumus biaya pokok sebagai berikut (Irwan \& Novita, 2016). Biaya pokok pengoperasian mesin pengiris adonan kerupuk merah tipe piringan pisau vertikal adalah sebagai berikut (Nurmeji et al., 2019; Putera et al., 2019):

$\mathrm{BP}=\frac{\frac{\mathrm{BT}}{\mathrm{X}}+B T T}{\mathrm{C}}=\frac{\frac{\mathrm{Rp} 1.141 .140}{1.470 \mathrm{jam} / \mathrm{thn}}+R p \cdot 16.949 / \mathrm{jam}}{291,438 \mathrm{~kg} / \mathrm{thn}}=\mathrm{Rp} 60,820 / \mathrm{kg}$

Keterangan:

$\mathrm{BP}=$ Biaya pokok $(\mathrm{Rp} / \mathrm{jam})$

$\mathrm{X}=$ Jumlah biaya kerja (Jam/tahun

$\mathrm{C} \quad=$ Kapasitas $(\mathrm{kg} / \mathrm{jam})$

\section{Break Event Point}

Break event point adalah keadaan alat atau mesin yang dihasilkan tanpa keuntungan atau rugi. Jumlah pendapatan sama besarnya dengan jumlah biaya. Analisis ini mempelajari pengaruh timbal balik antara pendapatan, biaya dan keuntungan (Hamid et al., 2019; Adhiatma et al., 2019; Ihsan et al., 2020)

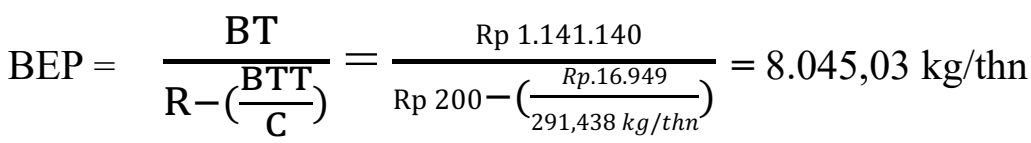

Keterangan :

$\mathrm{BEP}=$ Break event point $(\mathrm{kg} / \mathrm{tahun})$

$\mathrm{R} \quad=\mathrm{Upah} / \mathrm{sewa}$ alat $(\mathrm{Rp} / \mathrm{kg})$ 
Dari hasil perhitungan di atas di dapatkan hasil BEP mesin pengiris adonan kerupuk merah sebesar 8.045,03 kg/tahun.

\section{Kesimpulan}

Mesin pengiris adonan kerupuk merah tipe piringan pisau vertikal menggunakan motor listrik $1 / 2 \mathrm{hp}$ dengan kecepatan $1430 \mathrm{rpm}$, dengan imensi panjang $50 \mathrm{~cm}$, lebar $40 \mathrm{~cm}$, dan tinggi $70 \mathrm{~cm}$. Kapasitas mesin setelah dilakukan pengujian sebesar 291,348 kg/jam, dengan persentase kerusakan hasil potongan sebesar $38 \%$. Biaya pokok pada mesin pengiris adonan kerupuk merah tipe piringan pisau vertikal sebesar Rp. 60,820 /kg dan BEP sebesar 8.045,03 $\mathrm{kg} / \mathrm{thn}$.

Berdasarkan uji kinerja yang telah dilaksanakan mesin pengiris adonan kerupuk merah tipe piringan pisau vertikal berjalan dengan lancar, tetapi perlu diperhatikan untuk pengasahan mata pisau agar lebih tajam. Jarak atau ketebalan mata pisau tidak terlalu jauh, supaya pengirisan kerupuk tidak terlalu tebal dan juga penyetelan antar 3 mata pisau harus disamakan agar tebal irisan kerupuk menjadi setara tidak ada yang ketebalan dan atau juga ketipisan, dan mesin tidak hanya bisa menggunakan motor listrik tetapi juga bisa menggunakan motor diesel dengan skala besar agar dapat memproduksi lebih banyak tetapi berfungsi secara maksimal.

\section{Daftar Pustaka}

Adhiatma, A., Hidayat, R., Gusviandra, D., Rildiwan, R., Zulnadi, Z., Amrizal, A., \& Batubara, F. Y. (2019). Rancang Bangun dan Kinerja Mesin Pengupas Sabut Kelapa Muda. Agroteknika, 2(2), 85-94. https://doi.org/10.32530/agroteknika.v2i2.40

Azima, F., Putera, P., Oktaviyani, Zulfani, R., \& Hernando, R. (2018). Rancang Bangun Mesin Pengiris Buah Pinang Muda Tipe Horizontal. Agroteknika, 1(2), 63-76. https://doi.org/10.32530/agtk.v1i2.23

Baskara, I., Putera, P., Sari, I. H., Saputra, A., Ardianto, E. E., Darwisman, R., \& Ardianto, R. (2018). Rancang Bangun Mesin Pengiris Bawang Merah Tipe Vertikal. Agroteknika, 1(1), 39-50. https://doi.org/10.32530/agtk.v1i1.21

Ihsan, A. M., Ariyandi, Z., Wisaputra, S., Zulnadi, Z., Amrizal, A., Herdian, F., Nurtam, M. R., Batubara, F. Y., \& Defrian, A. (2020). Rancang Bangun Alat Perontok Kacang Tanah (Arachis hypogaea L.) Semi Mekanis Tipe Vertikal. Agroteknika, 3(1), 5566. https://doi.org/10.32530/agroteknika.v3i1.61

Irwan, A., \& Novita, S. A. (2016). Buku Kerja Praktek Mahasiswa (BKPM). Ekonomi Teknik. Payakumbuh: Politeknik Pertanian Negeri Payakumbuh

Jabbar, R. J., Ihsan, S., Gusnedi, P., \& Zuladha, A. (2018). Rancang Bangun Mixer Adonan Kerupuk Tipe Horizontal. Agroteknika, 1(2), 89-98. https://doi.org/10.32530/agtk.v1i2.26

Hamid, A., Lubis, Y. H., Hafis, H., Harahap, H., Yudistira, Y., Irzal, I., Djinis, M. E., \& Hasman, E. (2019). Rancang Bangun dan Kinerja Mesin Pencacah Tongkol Jagung. Agroteknika, 2(2), 64-74. https://doi.org/10.32530/agroteknika.v2i2.41 
Ratnawati, R. (2013). Eksperimen Pembuatan Kerupuk Ikan Banyar dengan Bahan Dasar Tepung Komposit Mocaf dan Tapioca. [Skripsi]. Semarang: Jurusan Teknologi Jasa dan Prosuksi, Fakultas Teknik, Universitas Negeri Semarang.

Nasution, M. A., Putra, G., Putra, A., \& Andika, S. (2018). Rancang Bangun Alat Pencacah Daun dan Ranting Gambir. Agroteknika, 1(1), 1-8. https://doi.org/10.32530/agtk.v1i1.16

Nurmeji, Lisman, F., Yuni, Syahriza, R., Nurtam, M. R., Djinis, M. E., Irzal, \& Amrizal. (2019). Rancang Bangun Alat Pemipil Jagung Sederhana. Agroteknika, 2(1), 11-19. https://doi.org/10.32530/agtk.v2i1.30

Putera, P., Intan, A., Mustaqim, F., \& Ramadhan, P. (2019). Rancang Bangun Mesin Pengupas Sabut Kelapa. Agroteknika, 2(1), 31-40. https://doi.org/10.32530/agtk.v2i1.31

Winarno, F. G. (1993). Kimia Pangan dan Gizi. Jakarta: PT. Gramedia Pustaka Utama. 